\title{
EDITORIAL
}

\section{Responses to the COVID-19 pandemic: Lessons learned from Qatar University College of Pharmacy}

\author{
Banan Abdulrzaq Mukhalalati (D), Ahmed Awaisu (D), Maguy Saffouh El Hajj (D) \\ College of Pharmacy, QU Health, Qatar University, Qatar
}

Correspondence

Dr Banan Abdulrzaq Mukhalalati

College of Pharmacy

QU Health

Qatar University

Doha

Qatar

banan.m@qu.edu.qa
The COVID-19 pandemic has resulted in a global emergency in all social realms including, economy, health, and education. In this article, we discuss the impact of COVID-19 pandemic on education, particularly higher education in the State of Qatar and the strategies adopted to respond to the challenge. The paper further discusses the use of educational technology and strategies for distance-based and blended learning during the pandemic.
In March 2020, World Health Organisation (WHO) declared the coronavirus disease 2019 (COVID-19) outbreak as a pandemic due to its alarming level of severity and wide spread across the globe (WHO, 2020). The unusual characteristics of the disease including transmission from person-to-person through droplets and contaminated surfaces, and by asymptomatic individuals as well as high infectivity and rapid spread, warrant early detection and strict preventive measures to minimise community transmission (Bai et al., 2020; Meselson, 2020). The coronavirus outbreak has resulted in interruption to daily life activities of billions of people around the world, including businesses, education, health and social life, as strict public health measures are being enforced to reduce the transmission of the disease.

Qatar precautionary measures in response to COVID-19 outbreak

The State of Qatar reported the first case of COVID-19 in February 2020. By March 2020, the Ministry of Public Health (MOPH) in Qatar urged all individuals to apply preventive measures to protect against infection, such as social distancing, using personal protective equipment, minimising the number of individuals attending workplaces, and self-isolation. Furthermore, the government of Qatar announced the closure of most businesses and institutions, including academic institutions and schools. The COVID-19 section of the Government Communications Office (GCO) has indicated that the 'precautionary measures may change based on the latest guidance by the national health authorities and international organisations regarding the spread of COVID-19' (GCO, 2020).

\section{Dealing with COVID-19 in the higher education sector in Qatar}

In the State of Qatar, the education sector was among the most affected. On 10th March, 2020, the government of Qatar through the Ministry of Education and Higher Education (MOEHE) announced the closure of all public and private schools, including institutions of higher learning, in order to control further spread of COVID-19, 
and students and teachers were directed to stay home. The MOEHE swiftly responded to this closure by designing effective alternative strategies to the traditional physical classroom teaching, such as distance-based learning platforms and digital learning materials to ensure the sustainability of students' learning (MOEHEa, 2020). All academic institutions of higher learning including universities complied with the guidelines and regulations issued by Qatar's MOEHE and the MOPH. The MOEHE was not strict on the types of platforms to be used for the delivery of teaching and learning, but instead circulated general guidelines to encourage the development of in-house strategies for the continuity of teaching and learning activities.

For the autumn semester of the 2020/21 academic year, August- November 2020, the MOEHE in collaboration with the $\mathrm{MoPH}$ resolved to implement a blended learning approach nationwide, and all higher education institutions were mandated to comply with this initiative (MOEHE, 2020a; 2020b). Accordingly, a combination of online learning technology and face-to-face classroom-based learning is offered at all stages of education.

\section{Qatar University and COVID-19 era: Challenges and opportunities}

Qatar University (QU) is the country's national institution of higher education. QU is comprised of ten colleges that offer a wide range of academic programmes, including 47 bachelors, 29 masters, 20 Ph.D programmss, nine diplomas, and a Doctor of Pharmacy (Pharm.D.) programme. The QU population is composed of a rapidly growing, diverse and lively body of over 23,000 students and 4,000 full-time faculty and staff members (QU, 2020a). On 10th March 2020, and in response to MOEHE announcement to suspend classes in public and private schools and universities, QU higher administration announced the continuation of the educational process through virtual learning platforms according to a regular schedule and the remote provision of academic support by the Student Learning Support Centre, Academic Advising Center, and digital library services (QU, 2020b). In order to facilitate the shift to online learning, all instructors were provided with a three-day emergency training about virtual learning platforms, such as Blackboard Collaborate Ultra, WebEX, Microsoft Team, and Zoom through the Centre for Excellence in Teaching and Learning, and instructors were expected to prepare their students for this shift (Naji et al., 2020). Furthermore, QU deliberated on the methods of evaluating students, benchmarking to best evaluation practices and taking in consideration the quality of the educational process and the need to reduce anxiety on students and faculty, and hence, QU guided faculty members to capitalise on the use of different formative evaluation methods, when feasible. Additionally, QU's Research and Graduate Studies Sector announced the launch of QU Emergency Response Grant (ERG), which constitutes part of the international research efforts dedicated to deal with COVID-19 and emergency circumstances. A series of seminars, conferences, and meetings were led and held by academic leaders and researchers from QU through e-platforms in order to discuss educational activities and research initiatives to confront the coronavirus pandemic, such as 'COVID-19: Challenges and Attitudes' conference, 'Post-Coronavirus Knowledge-based Economy' seminar, and 'Higher Education Post COVID-19 - New Era of Resilience, Lessons and Opportunities' seminar (QU, 2020c).

\section{College of Pharmacy, Qatar University pioneering processes for the quality assurance of education and training in response to COVID-19 pandemic}

The establishment of the College of Pharmacy (CPH) at QU in 2006 aimed to meet Qatar's growing demand for improved health outcomes and to comply with the third pillar of the Qatar National Vision (QNV) 2030, "human development', which focuses on providing educational programmes with the highest quality standards (Mukhalalati, Ashour, \& Al Noami, 2020). The CPH offers a Bachelor of Science (BSC.) degree programme and four post-baccalaureate degree programmes: Doctor of Pharmacy (Pharm.D.), Master of Science (MSc.) in Pharmaceutical Sciences, MSc. in Clinical Pharmacy Practice, and Doctor of Philosophy (Ph.D.) in Pharmaceutical Sciences (QU, 2020e). The CPH is accredited by the Canadian Council for Accreditation of Pharmacy Programmes for its BSc. and Pharm.D. programmes (QU, 2020d).

During the COVID-19 pandemic, CPH followed the QU latest updates and instructions very closely. With QU administration's decision to switch teaching to virtual learning, an emergency committee composed of the Dean, Assistant Dean for Student Affairs, Associate Dean for Academic Affairs, Department Heads and the Chair of the Assessment Committee was formed. The mandate of the committee was to ensure the continuity of quality teaching and assessment and the achievement of programme learning outcomes, while addressing all exceptional challenges imposed by COVID-19. The mandate of this emergency committee aligns with the 
global Pharmaceutical Development Goals related to workforce (DG[w]) introduced by the International Pharmaceutical Federation (FIP), particularly to DG[w]3, quality assurance (FIP, 2020). DG[w]3 involves the implementation of transparent, contemporary, effective, , and innovative policies and processes for the quality assurance of needs-based education and training systems (FIP, 2020).

The CPH's extensive utilisation of technology in teaching and assessment since its establishment in 2006 has equipped faculty, staff, and students with all the required components and best practices for the transition to distance learning. However, the utilisation of virtual platforms was optimised to facilitate the online delivery of lectures and assessments, enhance faculty-student interaction, and enable active student participation and engagement (AlrayyanTV, 2020). Several virtual meetings were conducted with faculty members to discuss appropriate platforms to use for each course, which aligns with its learning objectives. For example, the 'breakout room' feature of Zoom was used in debates and professional skills sessions to enable division of students into rooms of five to six students in order to conduct counselling role-plays or debate discussions. Likewise, Blackboard Collaborate Ultra was used for videotaping and uploading experiments in pharmaceutics lab on Blackboard, and online live sessions were delivered for further explanation. Furthermore, assessment plans were modified to align with QU guidelines, focusing primarily on formative assessment strategies, and exams were conducted virtually using Blackboard test tools after undergoing peer review by the college assessment committee. Moreover, a virtual Objective Structured Clinical Exam (OSCE) was developed and conducted by the Clinical Pharmacy and Practice Department using Zoom for fourth year professional students as part of their graduation requirement (QU, 2020g). Additionally, online platforms were also used by graduating Master of Pharmacy students to defend their thesis projects virtually (Gulf Times, 2020). For Pharm.D. experiential rotations, a containment approach was adopted where all Pharm.D. students were removed from the practice sites, and the Pharm.D. Director worked with the experiential education team to adjust the experiential part of the programme, and virtual clinical and academic rotations were designed and delivered for students by cross appointed faculty members (QU, 2020f). In order to maintain a high-quality of learning and training, students were contacted on a regular basis by the college administration to examine their virtual learning experience and to understand and respond to their educational needs. Examining students' perception of their virtual learning experiences in order to respond to their educational needs also aligns with WDG3, quality assurance, by defining critical stakeholder, including students, input on development of adequate education and training and fair and effective policies (FIP, 2016).

In conclusion, while virtual learning cannot completely replace face-to-face teaching, COVID-19 associated challenges have stimulated innovation in teaching and learning at QU CPH with the goal of ensuring the quality of education and the graduation of a critical mass of competent pharmacy workforce. This supply of competent, fit-for-purpose pharmaceutical workforce will ultimately contribute to achieving the Qatar National Vision 2030, nationally, nationally, global Pharmaceutical Development Goals related to workforce, particularly to $D G[w] 2$, capacity building, professionally, and the United Nations Sustainable Development Goals, globally (WHO, 2017; FIP, 2020; Mukhalalati et al., 2020).

\section{References}

AlrayyanTV. (2020). Part of the meeting with Dr. Muhammad Diab - Dean of the College of Pharmacy - Qatar University [Tweet 15/03/2020]. Available at: https://twitter.com/AlrayvanTV/status/ $\underline{1239221414810595329}$

Bai, Y., Yao, L., Wei, T., Tian, F., Jin, D.-Y., Chen, L., \& Wang, M. (2020). Presumed asymptomatic carrier transmission of COVID-19. Jama, 323(14), 1406-1407. https://doi.org/10.1001/jama.2020.2565

Chen, N., Zhou, M., Dong, X., Qu, J., Gong, F., Han, Y., et al. (2020). Epidemiological and clinical characteristics of 99 cases of 2019 novel coronavirus pneumonia in Wuhan, China: a descriptive study. The Lancet, 395(10223), 507-513.https://doi.org/10.1016/ S0140-6736(20)30211-7

Gulf Times. (2020). Pharmacy students present graduation projects virtually, 9th June, 2020 - Gulf Times Newspaper. Available at: https://www.gulf-times.com/story/665210/QUCollege-of-Pharmacy-students-present-graduation-projects-virtually

Huang, C., Wang, Y., Li, X., Ren, L., Zhao, J., Hu, Y., et al. (2020). Clinical features of patients infected with 2019 novel coronavirus in Wuhan, China. The Lancet, 395(10223), 497-506. https://doi. org/10.1016/S0140-6736(20)30183-5

FIP [International Pharmaceutical Federation]. (2016). Transforming the global pharmaceutical workforce. Pharmaceutical workforce development goals. Available at: https://www.fip.org/files/ content/priority-areas/workforce/wdgs-online-version.pdf

Meselson, M. (2020). Droplets and Aerosols in the Transmission of SARS-CoV-2. New England Journal of Medicine. https://doi.org/10. 1056/NEJMc2009324

MOEHE [Ministry of Education and Higher Education]. (2020a). COVID-19 Education Efforts, State of Qatar. Available at: https://www.edu.gov.qa/en/Pages/Corona.aspx 
MOEHE [Ministry of Education and Higher Education]. (2020b, September). Back-To-School Plan Amended to Adopt Blended Learning, State of Qatar. Available at: https://www.edu.gov. qa/en/mediacenter/pages/mediacenter/newsdetails.aspx? itemid $=177$

Mukhalalati, B., Ashour, M., \& Al Noami, A.E. (2020). Examining the motivations and future career aspirations of Qatari pharmacy students and alumni: A case study. Currents in Pharmacy Teaching and Learning, 12(11), 1329-1339. Available at: https://doi.org $\angle 10.1016 /$ j.cptl. 2020.06.003

Naji, K.K., Du, X., Tarlochan, F., Ebead, U., Hasan, M.A., \& Al-Ali, A.K. (2020). Engineering Students' Readiness to Transition to Emergency Online Learning in Response to COVID-19: Case of Qatar. EURASIA Journal of Mathematics, Science and Technology Education, 16(10). https://doi.org/10.29333/ejmste/8474

QU [Qatar University]. (2020a). About Qatar University. Available at: http://www.qu.edu.qa/about

QU [Qatar University]. (2020b). Coronavirus (COVID-19). Latest Announcements. Available at: http://www.qu.edu.qa/coronavirus

QU [Qatar University].(2020c, May). Research. Research Magazine. Available at: http://www.qu.edu.qa/static file/ qu/research/magazine/English-13.pdf

QU [Qatar University]. (2020d). College of Pharmacy. About. Accreditation. Available at: https://www.qu.edu.qa/pharmacy/ about/accreditation

QU [Qatar University]. (2020e). College of Pharmacy. Academic Departments. Programs. Available at: https://www.qu.edu.qa/ pharmacy/departments/programs

QU [Qatar University]. (2020f). Newsroom. Pharmacy. Clinical Placements. Available at: http://www.qu.edu.qa/newsroom/ Pharmacy/Clinical-placements-for-QU\%E2\%80\%99s-Doctor-of-Ph armacy-students-switch-to-Virtual-rotations-during-COVID\%E2\%8 0\%9319-pandemic

QA [Qatar University]. (2020g). Newsroom. Pharmacy. Available at: https://www.qu.edu.qa/newsroom/Pharmacy/(QU\%E2\%80 $\% 93 \mathrm{CPH}$ )-conducts-its-Final-Year-OSCE-Exam-online-during-COVID \%E2\%80\%9319

GCO [Government Communications Office]. (2020). Coronavirus (COVID-19). Available at: https://www.gco.gov.qa/en/focus/covid-19/

WHO [World Health Organization]. (2017). Tracking universal health coverage:2017. Global monitoring report. Available at: https://apps.who.int/iris/bitstream/handle/10665/259817/97892 41513555eng.pdf;jsessionid=3317DBE7B2A3DD085D12287FB978 B613?sequence $=1$

WHO [World Health Organization]. (2020). Timeline of WHO's response to COVID-19. Available at: https://www.who.int/ news-room/detail/29-06-2020-covidtimeline 